九州大学学術情報リポジトリ

Kyushu University Institutional Repository

\title{
On MOKUROKU File Based on "A Check List of Japanese Insects" on INTERNET
}

Tadauchi, 0samu

Inoue, Hitoshi

https://doi.org/10.5109/2643

出版情報: ESAKIA. 40，pp.81-84，2000-03-31. Entomological Laboratory，Faculty of Agriculture， Kyushu University

バージョン :

権利関係 : 


\title{
On MOKUROKU File Based on "A Check List of Japanese Insects" on INTERNET ${ }^{1), 2)}$
}

\author{
Osamu TADAUChI \\ Entomological Laboratory, Faculty of Agriculture, \\ Kyushu University, Fukuoka, 812-8581 Japan \\ and \\ Hitoshi INOUE \\ Computation Center, Kyushu University, Fukuoka, 812-8581 Japan
}

\begin{abstract}
A database file MOKUROKU based on "A Check List of Japanese Insects" is open to INTERNET as well as in the Computer Center of Kyushu University. Each record is composed of 5 items, i.e., scientific names of family, genus, species, Japanese name and distribution. A home page of the file, MOKUROKU using the database management system SIGMA is presented. A user can access the file by retrieving the following URL: http://konchudb.agr.agr. kyushu-u.ac.jp/mokuroku/index-e.html/.

Key words: entomology database, network, public use, MOKUROKU, INTERNET, SIGMA.
\end{abstract}

A database file MOKUROKU is based on "A Check List of Japanese Insects" (supervisor: Y. Hirashima, $1989 \& 1990$ ) and treats all the insect species or subspecies recorded from Japan. Each record is composed of 5 items, i.e., scientific names of family, genus, species (or subspecies), Japanese name and distribution. The MOKUROKU was constructed in the Computer Center of Kyushu University (1st edition, Tadauchi et al., 1990). It is managed by a text database management system SIGMA (Arikawa et al., 1987, 1988) working at the Computer Center of Kyushu University. The system SIGMA was recently modified for use on a work station. Therefore the MOKUROKU was revised for ease of retrieval and use for foreigners on a work station in the Entomological Laboratory, Kyushu University (Tadauchi and Inoue, 1999) and has been open to the public on INTERNET as well as from the Computer Center of Kyushu University since 1999. A user can get information in part

1) Contribution from the Entomological Laboratory, Faculty of Agriculture, Kyushu University, Fukuoka (Ser. 5, No. 38 ).

2) This work was partly supported by a Grant-in-Aid for Scientific Research from the Ministry of Education, Science, Sports and Culture, Japan (No. (B)(2) 09490028) (Head Investigator: O. Tadauchi). 
on new species and new recorded species from Japan by using another database KONCHU.

A user can access the KONCHU by retrieving the following URL: http:// konchudb.agr. agr.kyushu-u.ac.jp/mokuroku/index-e.html/.

The home page of the MOKUROKU using the SIGMA is presented in Figs. 1-2. The usage of the SIGMA system is explained in Arikawa et al. $(1987,1988)$.

\section{Acknowledgments}

We are grateful to Prof. Emeritus Y. Hirashima for permission of opening of the MOKUROKU to the public. We are also indebted to Prof. S. Arikawa, Head of the SIGMA Project Group of Kyushu University, Prof. Emeritus K. Morimoto and Prof. J. Yukawa of Kyushu University for their encouragements and various help.

\section{References}

Arikawa, S. et al., 1987. A text database management system SIGMA, Version 2. Koho, Computer Center Kyushu Univ., 20: 517-581. (In Japanese)

Arikawa, S. et al., 1988. SIGMA: A text database management system. RIFIS Techn. Rep. Res. Inst. Fundam. Inform. Sci., Kyushu Univ., CS-3: 1-16.

Hirashima, Y. (superviser), Entomological Laboratory, Faculty of Agriculture, Kyushu University and Japan Wild Life Research Center (eds.), 1989. A Check List of Japanese Insects. 1,767 pp, Fukuoka. (In Japanese)

Hirashima, Y. (superviser), Entomological Laboratory, Faculty of Agriculture, Kyushu University and Japan Wild Life Research Center (eds.), 1990. A Check List of Japanese Insects. Addenda and Corrigenda. 37 pp, Fukuoka. (In Japanese)

Tadauchi, O.et al., 1990. Database construction of "A Check List of Japanese Insects. Bull. Computer Sci., Computer Center Kyushu Univ., (7): 9-18. (In Japanese)

Tadauchi, O., 1996. Database production of species information in insects. pp.156-166, In Computer Center of Kyushu University (ed.), Essays Contributed in Celebration of the 25th Anniversary of Computer Center of Kyushu University. Fukuoka. (In Japanese) 


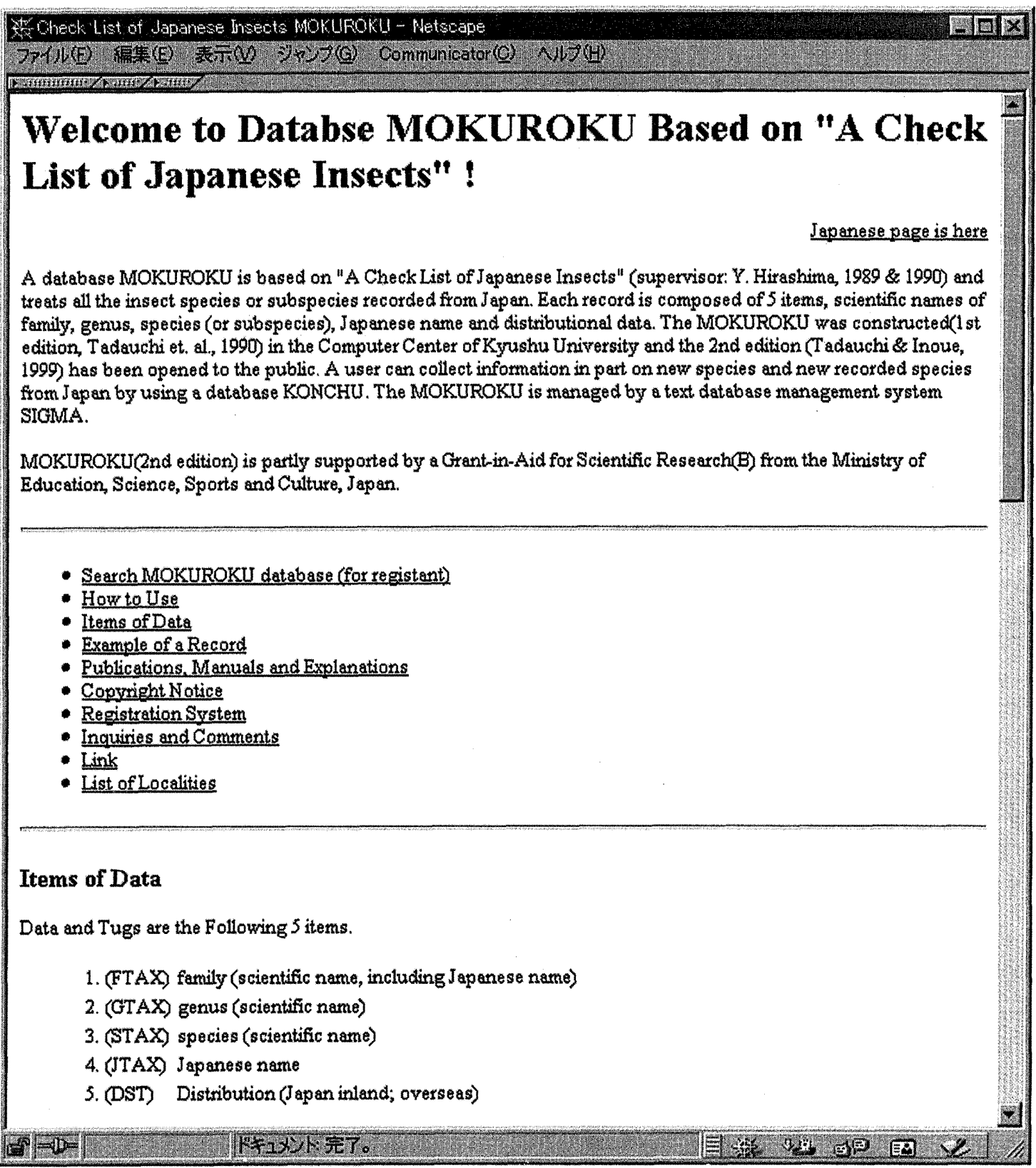

Fig. 1. A home page of a database MOKUROKU based on "A Check List of Japanese Insects" in English version. A Japanese version is also available.

URL: http://konchudb.agr.agr.kyushu-u.ac.jp/ mokuroku/index-e.html/. 


\section{Example of a Record}

(FTAX) 315180550000. Pieridae シロロテウウ科(A)

(GTAX) Pieris @g(Artogeia)

(STAX) rapae @s crucivora Boisduval,1836

(JTAX) モンシロギョウ

(DST) HOKKAIDO, Rebun Is., Rishiri Is., HONSHU, Sado Is., Izu Isls., Ogasawara Isls., Awajishima Is., Oki Is., SHIKOKU, Shodoshima Is., KYUSHU, Tsushima Is., Iki Is., Goto Is., Tanegashima Is., Yakushima Is., Tokara Isls., AmamiOshima Is., Tokunoshima Is., OkinawaHonto Is., Miyako Is., Ishigaki Is., Iriomote Is., Yonaguni Is.; Taiwan, Far East Continent

\section{Publications, Manuals and Explanations}

- Hirashima, Y. (superviser), Entomological Laboratory, Faculty of Agriculture, Kyushu University and Japan Wild Life Research Center (eds.), 1989, A Check List of Japanese Insects. 1,767 pp, Fukuoka. (In Japanese)

- Hirashima, Y. (superviser), Entomological Laboratory, Faculty of Agriculture, Kyushu University and Japan Wild Life Research Center (eds.), 1990, A Check List of Japanese Insects. Addenda. 37 pp, Fukuoka. (In Japanese)

- Tadauchi, O.et al., 1990, Database construction of "A Check List of Japanese Insects. Bull. Computer Sci., Computer Center Kyushu Univ., (7): 9-18. (In Japanese)

- Tadauchi, O. \& H. Inoue, 1999. Construction of MOKUROKU file (2nd edition) on "A Check List of Japanese Insects". Computer Center News, Computer Center Kyushu Univ., No. 586.

\section{Copyright Notice}

Entomological Laboratotry, Faculty of Agriculture, Kyushu University holds the copyright on the MOKUROKU file (Head constructor: $O$. Tadauchi).

\section{Registration System}

The use of data in this database is free of charge if the objective is academic study or educational purposes. However, the user should be registered with the following address and then he or she will be received an user ID and a password, or please fill out this form. The user ID and password can be used in common with KONCHU database.

\section{Inquiries and Comments}

Inquiries and Comments about MOKUROKU Should be the Following E-mail Address.

Database MOKUROKU (Osamu Tadauchi)

Entomological Laboratory,

Faculty of Agriculture,

Kyushu University

Fukuoka, 812-8581

Japan

Phone: +81-92-642-2838 FAX: +81-92-642-2839

E-mail: tadauchi@agr.kvushu-u.ac.jp

Fig. 2. A home page of a database MOKUROKU (continued). 